\title{
Developing understanding and enactment of professionalism: undergraduate dental students' perceptions of influential experiences in this process
}

\author{
A. Ranauta, ${ }^{\star 1}$ D. Freeth ${ }^{2}$ and E. Davenport ${ }^{1}$
}

\section{Key points}

Identifies student perceptions of influential experiences in the process of developing their understanding and enactment of professionalism.

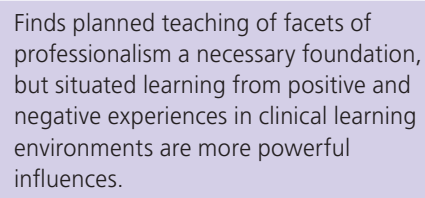
professionalism a necessary foundation but situated learning from positive and negative experiences in clinical learning environments are more powerful influences.

Underlines the importance of role modelling. Suggests attention to the role of emotion in learning and the development of professionalism.

Introduction Dental schools teach and assess professionalism, yet there is little research to inform curriculum concerning what students perceive to be powerful influences on their developing understanding and enactment of professionalism. Aim To identify experiences which dental students found influential in developing their understanding and enactment of professionalism. Methods Focus groups with students in each year of a five-year undergraduate dental curriculum in a UK dental school. Inductive thematic analysis, creating a descriptive account, then theoretically informed analysis, using the lens of situated learning in communities of practice, producing an explanatory account. Results Students identified three clusters of influential learning experiences: planned teaching of facets of professionalism; experiencing powerful emotions triggered by clinical work; and role modelling in clinical environments. Better understanding of professionalism arose from positive and negative experiences: students developed the ability to reframe negative experiences into positive learning and commitment. Conclusions In this study, experiences within clinical environments strongly influenced students' developing understanding of professionalism, underpinned by formal university teaching and personal reflection. The greatest influences included role modelling and experiences that generated strong emotions. Other studies have highlighted role modelling. Further study of the role of emotion in the process of developing professionalism may be warranted.

\section{Introduction}

Over the last quarter century expectations and understandings of professionalism have changed within health professions and wider society. ${ }^{1}$ The General Dental Council (GDC) describes professionalism as 'the knowledge, skills, attitudes and behaviours required to practise in an ethical and appropriate way, putting patients' needs first and promoting confidence in the dental team.' ${ }^{2}$ Registrants' professionalism is a key focus for regulators and dental schools. Dental curricula include early patient contact and supervised clinical practice. Thus,

IInstitute of Dentistry, Barts and The London School of Medicine \& Dentistry, Queen Mary, University of London, Turner Street, London, E1 2AD; ${ }^{2}$ Royal College of Physicians, 11 St Andrews Place, London, NW1 4LE

${ }^{*}$ Correspondence to: Dr Amitha Ranauta

Email: a.ranauta@qmul.ac.uk

Refereed Paper.

Accepted 7 August 2018

Published online 5 October 2018

DOI: $10.1038 /$ sj.bdj.2018.813 it is also essential that students can demonstrate the attributes of professionalism at all times from the beginning of their training. ${ }^{3}$ There is an expectation that teaching and assessment of professionalism are woven throughout all UK undergraduate dental programmes. More research into the development of professionalism during these curricula is needed. ${ }^{4,5}$

Medical education has shaped much of what is understood about teaching and assessment of professionalism. ${ }^{6,7}$ Cultural changes in teaching hospitals and university departments have been advocated, including more supportive learning environments that promote self-reflection and group-reflection. ${ }^{8}$ However, medical students' perceptions of inconsistency between academic teaching of professionalism and realties of clinical work have been reported, ${ }^{9}$ highlighting the possible influence of the 'hidden curriculum' (implicit messages from the learning context and experience). It has been argued that these inconsistencies may influence the development of students' professional identities (for example as a dental practitioner) more than formally taught behaviour. ${ }^{10,11}$ This promotes cynicism as individuals learn that taught principles are not always matched in daily practice among their role models in clinical environments. ${ }^{12}$

Situated learning theory suggests that learning occurs through social interaction as learners engage within a 'community of practice' (CoP). ${ }^{13}$ Learners develop along a continuum from novice to expert by observing, practising and reflecting while developing social relationships with those in their environment. Situated learning suggests that early learners start at the periphery of a CoP, participating through observation, interaction and contributing assigned and supervised work. As they gain experience and expertise, they move more fully into the CoP through a process of socialisation and development of professional identity and expertise, eventually becoming recognised as practitioners within the $\mathrm{CoP} \cdot{ }^{14}$ Using a photographic analogy, $\mathrm{CoP}$ can be seen with a wide-angle lens as the entire community of the dental profession and its professional activities; or zooming in, $\mathrm{CoP}$ can refer to a single clinical environment. In the latter perspective, dental 
students experience many CoPs in a variety of clinical environments; their undergraduate learning is very much situated in the diversity and unpredictability of the dental clinics which support and supervise them.

The aim of this study was to explore which learning experiences dental students perceived as influential in developing their understanding and enactment of professionalism. In turn, this could inform the development of dental curricula.

\section{Study site}

A large dental school in the south of England working within clinical environments serving a very large and highly diverse population with above average levels of geographical mobility and socioeconomic deprivation, with associated health and health service challenges. The student journey is typical of most UK dental schools, an intensive programme over five years. The first two years of the curriculum focus on preclinical academic study of basic biological principles. Students are also taught clinical skills (first using simulation manikins), ethics and law, and communication skills (including role-play simulation); they start caring for patients towards the end of Year 2. In Years 3 and 4 university-based study decreases and students increase their clinical experience at the main dental hospital and in outreach centres. In Year 5, students consolidate their knowledge and clinical skills, continuing patient care in preparation for registration as a 'safe beginner.'2

Groups of eight to ten dental students, in pairs and supervised by a clinical tutor, work in dental clinics which are also staffed in the normal way by dental nurses and receptionists, domestic staff, visiting technicians, etc. The tutors may be clinical academics or general dental practitioners. Students rotate through a variety of clinics to gain diverse experiences. As students progress through the curriculum they take increasing responsibility for more complex care. In each of the large number of clinics, the clinical tutors and wider workforce are role models as they perform their professional responsibilities. Dental students outnumber qualified dentists in these clinics.

\section{Methods}

The university ethics board granted approval for the study. Participation was invited by email or letter, signed by AR and ED, accompanied by an information sheet outlining the details of the study. AR and ED were clinical academics in the

Table 1 Topic guide used to facilitate the focus groups with undergraduate dental students

\begin{tabular}{l|l} 
Purpose & Questions \\
\hline Engagement questions & $\begin{array}{l}\text { What does your dentist do when they are at their best? } \\
\text { What does your dentist do when they are not at their best? } \\
\text { What do you understand by professionalism? }\end{array}$ \\
\hline Exploration questions & $\begin{array}{l}\text { Can you remember being taught about professionalism during your undergraduate } \\
\text { Curriculum? } \\
\text { Were there any learning experiences/placements/role models/interactions that } \\
\text { you felt impacted on development of professionalism? } \\
\text { Did your environment influence the development of professionalism? }\end{array}$ \\
\hline Exit question & Is there anything else anyone would like to say? \\
\hline Helpful prompts & $\begin{array}{l}\text { Can you tell me a little more? } \\
\text { What do you mean? } \\
\text { What do the others think about this? }\end{array}$ \\
\hline
\end{tabular}

dental school and the invitation included the following reassurance: 'You should only agree to take part if you want to; it is entirely up to you. If you choose not to take part there won't be any disadvantages for you and you will hear no more about it.'

Purposive sampling ${ }^{15}$ of the undergraduate dental student population registered in 2012 $(\mathrm{N}=375)$ used a sampling frame including year of study, gender, whether the student had joined the dental programme as a school leaver or after other degree-level studies, and programme (BDS/Dip*). This supported diversity of study participants. Written informed consent was obtained from participants before commencement of data collection.

A pilot focus group provided rehearsal of data collection and supported development of the final topic guide (Table 1). Data collection comprised six three-phase (engagement, exploration, exit) focus group discussions, ${ }^{15}$ facilitated by AR; one for each year of the five-year dental programme. An additional mixed-year focus group was provided for students who wished to participate and could not attend their year group's discussion. The target group size was six to eight, to allow active participation by everyone. ${ }^{16}$ Students were encouraged to reflect broadly on all their learning experiences, planned and unplanned. AR took notes as back-up for the audio-recording of each discussion.

The process of data analysis included data management, descriptive accounts and explanatory accounts, as described by Ritchie and Lewis. ${ }^{17}$ Audio-recordings were transcribed and anonymised, using the following labelling system: Student $(\mathrm{S})$, their year of study (1-5), gender male $(\mathrm{M})$ or female $(\mathrm{F})$ and a unique identifier number. Following good practice, ${ }^{18}$ two researchers (AR and an experienced colleague, JK) reviewed and coded the six focus group transcripts independently, generating the initial descriptive account. Subsequent cycles of analysis, involving all authors, supported refinement of research questions, hypothesisdevelopment and pursuit of emerging lines of enquiry to elaborate themes and add depth to the analysis. ${ }^{18}$ The influence of situated learning was considered during formulation of the explanatory account. Finally, the original transcripts and thematic coding were revisited to ensure the explanatory account reflected the data accurately.

\section{Results}

Forty-eight students participated in focus groups lasting 90 minutes (eight Year 1, eight Year 2, nine Year 3, eight Year 4, seven Year 5; eight Mixed group; 25 female, 23 male; 35 school leaver entrants, 13 graduate entrants; 44 BDS, four Dip*). Analysis revealed three major themes describing learning experiences which dental students perceived as influential in the development of their understanding and enactment of professionalism.

\section{Theme 1: planned teaching of facets of professionalism}

Students experienced planned teaching of facets of professionalism across the dental curriculum. They regarded a significant proportion of this, particularly within the pre-clinical curriculum, as a necessary foundation for understanding the multifaceted nature of professionalism and beginning to develop their own professional behaviours. Learning the core knowledge and technical skills of being a dentist was considered fundamental, as one senior student put it: 
'As a fellow professional then you would put knowledge and technical skills high on the agenda for what makes a good dentist' (S2, F4).

Students valued formal teaching of ethical principles and concepts as a foundation for underpinning healthcare decision making and developing understandings of professionalism. The following quotations illustrate widely-held appreciation of classroom teaching of health care ethics:

'I'd say all the Human Science and Medical Ethics lectures' (S2, M8).

'She [ethics lecturer] taught me the one golden rule, which is do as you would be done by and I'll never forget that' (S3, F9).

Students identified the importance of communication skills teaching and its application to clinical practice, including understanding and enactment of professionalism:

'I think a lot of what we've done this year with the communication skills things, and it guides you with the sort of approach to take to patients' (S2, F6).

This theme confirms recognition of the contribution of planned teaching of facets of professionalism, including knowledge, practical skills, critical thinking, self-awareness and reflective practice.

\section{Theme 2: experiencing powerful emotions triggered by clinical work}

Students were motivated to care for patients and were enthusiastic about this part of the curriculum. They often described facets of clinical work which triggered powerful emotions, identifying these as impactful for the development of their understanding and enactment of professionalism. Most frequently the emotions were a bundle of feelings associated with taking responsibility for patient care. A second subtheme encompassed challenging encounters with, or in the presence of, patients.

\section{Taking responsibility for patient care}

Clinical learning in the undergraduate dental curriculum focuses on the provision of patient care. The transition from simulation and observation to providing dental care under supervision commenced towards the end of Year 2. A junior student described the anticipated enormity of this transition, comparing it to growing up and becoming independent. The words 'rushed' and 'suddenly' draw attention to perceptions of: readiness for the transition; swift passage of time to transition; and an abruptness in the transition to having responsibility for patient care:
'Some of the people here are quite young you know and need to, not to be rushed into it but obviously next year we're going to have patients which is quite a big transition from living at home, being a child really and suddenly you're in charge of people's health' (S1, M3).

A middle-year student summarised sentiment that had resonance among many students: he explained how individual responsibility for patient care was pivotal in the development of his enactment of professionalism. It caused him to 'act professional'; 'act' professional rather than 'be' professional perhaps implying that performing the professional behaviours of a dentist did not yet feel wholly natural:

'The actual physical act of treating a patient I think makes you step up, makes you act professional' (S3, M5).

Similarly, a senior student explained how taking on the responsibility for patient care was central to the development of her sense of professionalism:

'It [the responsibility] doesn't sink into you, until I think you start second year and seeing patients' (S4, F1).

The clinical tutor has vicarious responsibility for patients' wellbeing. This can impact on students' autonomy, particularly in the early stages when closer supervision and more frequent tutor intervention may be necessary. A senior student reflected that in her early weeks of treating patients she felt the supervising clinical tutor was largely responsible for her patient. As she progressed, she felt she had taken responsibility for patient care herself: a journey toward autonomous practice and feeling like a professional dentist:

'The patient is more their [tutor's] responsibility but when you get further on, you're doing everything by yourself and it's your own decision making and your own relationship and you hardly consult the tutors, you actually feel like a professional dentist as opposed to a student' (S5, F2).

\section{Challenging encounters with, or in the presence of, patients}

Many students recalled challenging encounters with or in the presence of patients, which triggered powerful emotions such as overload, fear, embarrassment, relief, appreciation, empowerment or pride. The power and impact of most encounters described in this context hinged on students' perceptions and reactions to clinical tutors' behaviour. Both constructive and adverse encounters influenced students' emotions and developing sense of professionalism. Adverse experiences did not necessarily weaken a student's understanding or enactment of professionalism, if these experiences could be reconstructed as positive learning. For example, during the Year 3 focus group a student described adverse experiences and negative emotions affecting her sense of professionalism:

'I get nervous, if a tutor has said anything bad about you in front of a patient or anything again, going back to how tutors interact with us as well, it just turns me into a mess' (S3, F8)'

A peer responded:

'I think it's scenarios and experiences like those that test our professionalism, and how you treat that, as well as the good points and the bad points is also part of the learning experience' (S3, M5).

Elsewhere, a senior student recalled a challenging consultation with a patient, requiring tutor intervention. This emotionally charged situation unnerved the student, however, observation of how the clinical tutor managed it helped the student to develop. On reflection, this was remembered as a positive learning experience aiding the development of professional behaviours:

'I remember one incident in oral surgery where a lady was screaming even though she had a good six injections and I didn't know how to manage her so I was panicking as well and then my tutor came along. The tutor just did it, and I was really impressed with that, so observing how tutors manage difficult scenarios helped me in my experiences' (S5, F5).

\section{Theme 3: role modelling in clinical environments}

Dental students were highly motivated to develop their professional role within clinical environments providing a range of dental care for diverse patient needs. Students recalled how positive and negative behaviours of colleagues influenced their developing sense of professionalism. (From the student perspective, colleagues mainly included supervising clinical tutors, nursing and reception staff, and other students.) The role modelling of clinical tutors was an important factor in learning professional attitudes and behaviours which the dental students wished to replicate:

'The best way of learning about professionalism is watching someone who's got vast experience and has been there and done it, and yes, copying' (S2, M8).

Students reported positive role modelling in a wide range of contexts and appreciated the expertise and support of colleagues, while noting negative behaviours they did not wish to emulate.

Junior students often looked up to senior students in clinical environments: 
'I think it's sometimes nice when you're on clinic when you see students that are fourth or fifth year but they're working with a patient and you're thinking in your head yeah I want to be like that' (S1, F7).

Negative influences mostly related to belittling and inconsiderate behaviours. For example, poorly delivered feedback, particularly in the presence of others, could cause a setback in development by undermining students' confidence (for example, see S3, F8 in previous section) and a feeling of belittlement straining the enactment of professionalism is described in the next quotation:

'When it's very much the teachers in charge and they know best and you are treated like a child it makes it very difficult to be professional with them. I certainly struggled when I was spoken to like a child because I think well actually I'm not, I'm an adult and okay I'm not a qualified dentist yet but I treat you with respect so I think it needs to work both ways' (S4, F7).

Discerning poor role modelling from colleagues of any profession or career stage could clarify students' perceptions of poorly enacted professionalism and encourage their resolve to enact professionalism differently, for example:

'You can see certain tutors, not really acting professionally. Their attitudes, time management and all I used to think was I hope I'll never be like that' (S4, F4).

\section{Discussion}

The concept of professionalism is hard to pin down. It is defined through documented definitions, embedded in curriculum design and delivery, and also given shape and meaning by dental students as they engage with everyday clinical practice. Taylor and colleagues highlighted how conceptualisation of professionalism can affect curriculum design, ranging from courses designed to teach professionalism by didactic methods, to programmes relying on situated learning focused on a goal of students internalising values and norms. ${ }^{19}$ In common with many dental programmes, the curricula in this study site address the development of professionalism through targeted knowledge and skill development in the early years, then rely mainly upon situated learning in clinical practice and students' ability to reflect upon experiences and to be self-aware. This learning journey is under-researched. ${ }^{20}$ Therefore, this study aimed to explore which learning experiences undergraduate dental students perceived as influential in developing their understanding and enactment of professionalism. In turn, this could inform the development of dental curricula.

The students contributing to this study identified ethics teaching in the pre-clinical phase as important support for developing understanding of professionalism: it helped to identify, examine and strengthen the morals and virtues expected of a professional dentist. The importance of value-based professionalism, which is driven by attitudes, reflection and practical wisdom (rather than seen as rooted in specific behaviours) is emphasised in the framework developed by Brody \& Doukas, which also considers professionalism as a 'trust-generating promise. ${ }^{21}$ Furthermore, students highlighted classroom and simulation learning relating clinical and communication skills as influencing their enactment of professionalism and their preparedness for supervised practice as novices within diverse clinical environments.

Once dental students' learning is predominantly situated within clinical environments, ${ }^{13}$ learning opportunities and outcomes are less predictable, decisions are more complex and there are many competing demands for students' attention. The development of professionalism evolves: situated within observing the practice of colleagues; accepting the weighty responsibility of patient care; developing technical and communication skills; understanding the realities of daily practice; and developing selfmanagement skills such as timekeeping and resilience. Students in this study emphasised the importance of tutors as role models and described role modelling of variable quality. The literature reinforces the importance of teachers as positive role models, ${ }^{22}$ and Hilton and Slotnick described influences such as negative role models as an 'attrition' in the development of medical students' professionalism. ${ }^{23}$

When treating patients and being observed by clinical teachers, students have to engage with many different aspects of dental care and professionalism, and contend with multiple social interactions. This is challenging and can feel overwhelming. The stakes are high and there are consequences if mistakes are made. This type of environment has the potential to evoke strong emotions. Students in this study particularly highlighted the emotions associated with accepting responsibility for patient care and they described emotionally-charged encounters with patients, or with colleagues in the presence of patients. The role of experiences which generate strong emotions receives little attention in the literature on professionalism; possibly a legacy of the tradition of framing professionalism as linked to emotional detachment. ${ }^{24}$ Looking elsewhere, Illeris' model of learning ${ }^{25}$ may offer analytical strength for future analyses. In this model, learning is conceptualised as a triangular 'tension field' defined by interplay between three 'poles' (the nature or content of what is being learnt, the learning environment and the learner's emotions).

As predicted by situated learning theory, ${ }^{13}$ students observed patterns of behaviour, the way people treated each other and the way they themselves were treated. Social interaction within the clinical environment was seen as an important factor in learning professional attitudes and behaviours which the dental students wished to replicate and identifying attitudes and behaviours from which they wished to distance themselves. This helped students to develop their understanding and enactment of professionalism, which was linked to a growing sense of personal identity as a professional dental practitioner. Students reacted differently to similar experiences. The schematic representations of professional identity formation developed by Cruess and colleagues suggest that differing reactions to similar experiences might be expected to arise from the influences of individual biographies, psychological and social processes. ${ }^{26}$

Students participating in this study described how an overall professional environment motivated them to behave professionally. They reported positive environments which created a culture of professionalism and tutors who provided responsive clinical and emotional support. This helped them to feel more confident as student clinicians. There were also negative experiences, which many students were able to reframe as positive learning. Over the five-year programme, varied experiences allowed the dental students to mature and make the transition to confident clinicians. Branch and Paranjape ${ }^{27}$ promote the potential of feedback and reflection to support this process and constructively influence the development of professionalism, even with negative learning experiences.

\section{Study limitations}

This study included self-selecting participants from one dental school, which may limit the breadth and applicability of the findings. Nevertheless, this dental school has a curriculum that is typical in the UK and the student population is similar to other dental schools in the UK. 
$\mathrm{AR}$ and $\mathrm{ED}$ were clinical academics at the dental school. Pre-existing relationships or reputations may have influenced (positively or negatively) students' agreement to participate in the study. The assurance within the study information sheet (see methods section) may have been insufficient for some, but this was difficult to detect. The effect may have been stronger in respect of AR, who facilitated the focus groups: possibly affecting participation in the study and contributions to focus group discussions. At the beginning of each focus group AR described the dominance of her researcher role during that time. The researchers kept reflective research journals and scrutinised the data for signs of reactivity to their dual roles of researcher and clinical academic: they found very little evidence of reactivity. Holding joint roles meant that AR and ED were familiar with curriculum components and clinical environments described by the students. This offered benefits of recognising the contextualisation of experiences described by students and understanding connections that students made. It helped AR to use well-targeted follow-up questions during focus groups. However, it also increased the potential for biases and presumptions. DF was independent of the dental school and her questioning of the data and provisional interpretations helped to clarify understandings and challenge presumption.

It is possible that the study participants were more interested in professionalism than their peers. Nevertheless, their identification of experiences which were influential in developing their understanding and enactment of professionalism provides insights that could be probed further with other dental students. If they have wider applicability, these insights could be used to shape evolving dental curricula and guide the professional development of role models, particularly clinical tutors.

Only six focus groups were conducted. However, the descriptive and explanatory analyses were conducted rigorously, and the explanatory account encompasses all descriptive themes. The emergence of new themes ceased before coding of focus group transcripts was complete, giving reasonable confidence in obtaining a comprehensive descriptive thematic framework as the foundation for trustworthy findings. Sufficient resonance was found between this study's findings and the wider literature about medical and dental professionalism to suggest that student perceptions in this context could resonate elsewhere.

\section{Conclusion}

This study found that planned, unplanned, positive and negative experiences all contribute to dental students' developing understanding and enactment of professionalism. Experiences within clinical environments were most influential but underpinned by personal reflection and planned teaching of facets of professionalism. Reactions to similar experiences varied between students and within the same student as time passed. Within clinical environments, the greatest influences included role modelling and experiences that generated strong emotions. Other studies have examined the impact of role modelling, but the role of emotion is underresearched. It would be useful to replicate this study in other settings. More broadly, further study of the role of emotion in the process of developing professionalism may be warranted.

If replicated, the findings of this study suggest that dental schools could support students' developing understanding and enactment of professionalism by: anticipating and embracing the unpredictability of situated learning in clinical environments; providing opportunities for role models to understand their influence and increase their expertise; paying more attention to the emotional components of learning and the influence of individual biographies; and anticipating the occurrence of negative experiences and supporting students' reframing of these.

\section{Endnote}

*Programmes: five-year Bachelor of Dental Surgery (BDS) or a small cohort of Diploma in Dental Hygiene and Therapy students studying alongside BDS students in Years 2 and 3.

\section{Acknowledgement}

With thanks to Jenny King (JK) for providing independent inductive analysis and discussing earlier drafts of this paper.

1. Cruess, Richard L, Cruess, Sylvia R. Expectations and Obligations: Professionalism and Medicine's Social Contract with Society. Perspect Biol Med 2008; 51: 579-598.

2. General Dental Council. Preparing for practice Dental team learning outcomes for registration. 2015. Available at https://www.gdc-uk.org/professionals/students-and-trainees/learning-outcomes(accessed December 2017).

3. General Dental Council. Standards for the Dental Team. 2013. Available at https://www.gdc-uk.org/api/files/
NEW\%20Standards\%20for\%20the\%20Dental\%20Team. pdf (accessed December 2017).

4. Zijlstra-Shaw S, Roberts T, P G R. Evaluation of an assessment system for professionalism among dental students. Eur J Dent Educ 2016; 21: e89-e100.

5. Trathen A, Gallagher J E. Dental professionalism: definitions and debate. Br Dent J 2009; 206: 249-253.

6. Jha V, Bekker H L, Duffy $S$ R et al. A systematic review of studies assessing and facilitating attitudes towards professionalism in medicine. Med Educ 2007; 41: 822-829.

7. Birden H, Glass N, Wilson I et al. Teaching professionalism in medical education: a Best Evidence Medical Education (BEME) systematic review. BEME Guide No. 25. Med Teach 2013; 35: e1252-1266.

8. Jones W S, Hanson J L, Longacre J L. An intentional modeling process to teach professional behaviour: students' clinical observations of preceptors. Teach Learn Med 2004; 16: 264-269.

9. Kavas M V , Demiroren M, Kosan A M et al. Turkish students perceptions of professionalism at the beginning and at the end of medical education: a cross-sectional qualitative study. Med Educ Online 2015; 20: 26, 614.

10. Cruess S R, Cruess R L, Steinert Y. Role modellingmaking the most of a powerful teaching strategy. BMJ 2008; 336: 718-721.

11. Levenson R, Atkinson S, Shepherd S. Understanding the doctors of tomorrow, The King's Fund. 2010. Available at https://www.kingsfund.org.uk/sites/default/files/ Understanding_the_doctors_of_tomorrow.pdf (accessed December 2017)

12. Inui T S. A Flag in the Wind: Educating for Professionalism in Medicine. Association of American Medical Colleges. 2003. Available at https://members.aamc.org/eweb/upload/A\%20 Flag\%20in\%20the\%20Wind\%20Report.pdf (accessed November 2017).

13. Lave J, Wenger E. Situated learning: legitimate peripheral participation. Cambridge: Cambridge University Press, 1991.

14. Reed. D W H, Hopper, T, Nicholls B. Influential Journey's through dental communities of practice: A Phenomenological based enquiry approach. AJPP Adv J Profession Pract 2017; 1: 2-14

15. Then K L, Rankin J A, Ali E. Focus group research: what is it and how can it be used? Can J Cardiovasc Nurs 2014; 24: $16-22$.

16. Krueger R A. Focus groups: a practical guide for applied research. 2nd edition. Thousand Oaks; London: Sage, 1994.

17. Ritchie J, Lewis J. Qualitative research practice: a guide for social science students and researchers. London: Sage Publications, 2003.

18. Silverman D. Interpreting qualitative data: methods for analysing talk, text and interaction. London: Sage, 2001.

19. Taylor C, Grey N, Checkland K. Professionalism... it depends where you're standing. Br Dent J 2017; 222: 889-892.

20. Field J, Ellis J, Abbas C et al. Teaching and assessment of professional attitudes in UK dental schools - commentary. Eur J Dent Educ 2010; 14: 133-135.

21. Brody H, Doukas D. Professionalism: a framework to guide medical education. Med Educ 2014; 48: 980-987.

22. Byszewski A, Hendelman W, McGuinty C et al. Wanted: role modelsmedical students' perceptions of professionalism. BMC Med Educ 2012; 12: 115.

23. Hilton S R, Slotnick H B. Proto-professionalism: how professionalisation occurs across the continuum of medical education. Med Educ 2005; 39: 58-65.

24. Phillips S P, Dalgarno N. Professionalism, professionalization, expertise and compassion: a qualitative study of medical residents. BMC Med Educ 2017; 17: 21.

25. Illeris K. How we learn: learning and non-learning in school and beyond. London: Routledge, 2007.

26. Cruess R L, Cruess SR, Boudreau J D et al. A schematic representation of the professional identity formation and socialization of medical students and residents: a guide for medical educators. Acad Med 2015; 90: 718-725.

27. Branch W T, Jr. Paranjape A. Feedback and reflection: teaching methods for clinical settings. Acad Med 2002; 77 1185-1188. 